KidsVUe • Issue One

\title{
CREATIVITY AND PROBLEM SOLVING: HOW TO SURVIVE ON A DESERTED ISLAND
}

Nicole Nguyen ${ }^{1}$, Jacqueline $\mathrm{Oh}^{1}$, Jesse Oler ${ }^{1}$

${ }^{1}$ Vanderbilt University, Nashville, TN, USA

Published on: Mar 05, 2021

DOI: 10.21428/99bbfa06.070061b7

License: Creative Commons Attribution 4.0 International License (CC-BY 4.0). 


\title{
CREATIVITY AND PROBLEM SOLVING: HOW TO SURVIVE ON A DESERTED ISLAND
}

Nicole Nguyen, Jacqueline Oh, \& Jesse Oler

Vanderbilt University, Nashville, TN, USA

\begin{abstract}
You are stranded alone on a deserted island. How will you survive the many challenges that this situation presents? In this paper, we will discuss common mental obstacles like mental set and functional fixedness that can prevent effective problem solving. To help you overcome these challenges, we will first discuss the important role creativity plays when it comes to solving problems. Then, using cognitive psychology concepts such as preinventive forms, solitude, and insight, we will help you think outside the box to survive, find food, and build shelter on the island.
\end{abstract}

\section{INTRODUCTION}

"Get up, we have to keep moving!" You suddenly awaken to your brother Alex dragging you onto the beach. You find yourself on a deserted island in the middle of the Pacific Ocean. Fighting through the pain in your forehead, you remember that your boat crashed into a coral reef and your guide, Captain Maxcey, is nowhere to be found. How are you going to survive and escape from the island with only the items found on the boat and the beach? By using problem solving techniques that involve your human creativity and insight as well as by overcoming the problems of functional fixedness and mental set, this paper will give you a guide to island survival so you can make it back home safely!

\section{SURVIVING WITH CREATIVITY: PRE-INVENTIVE FORMS AND SOLITUDE}




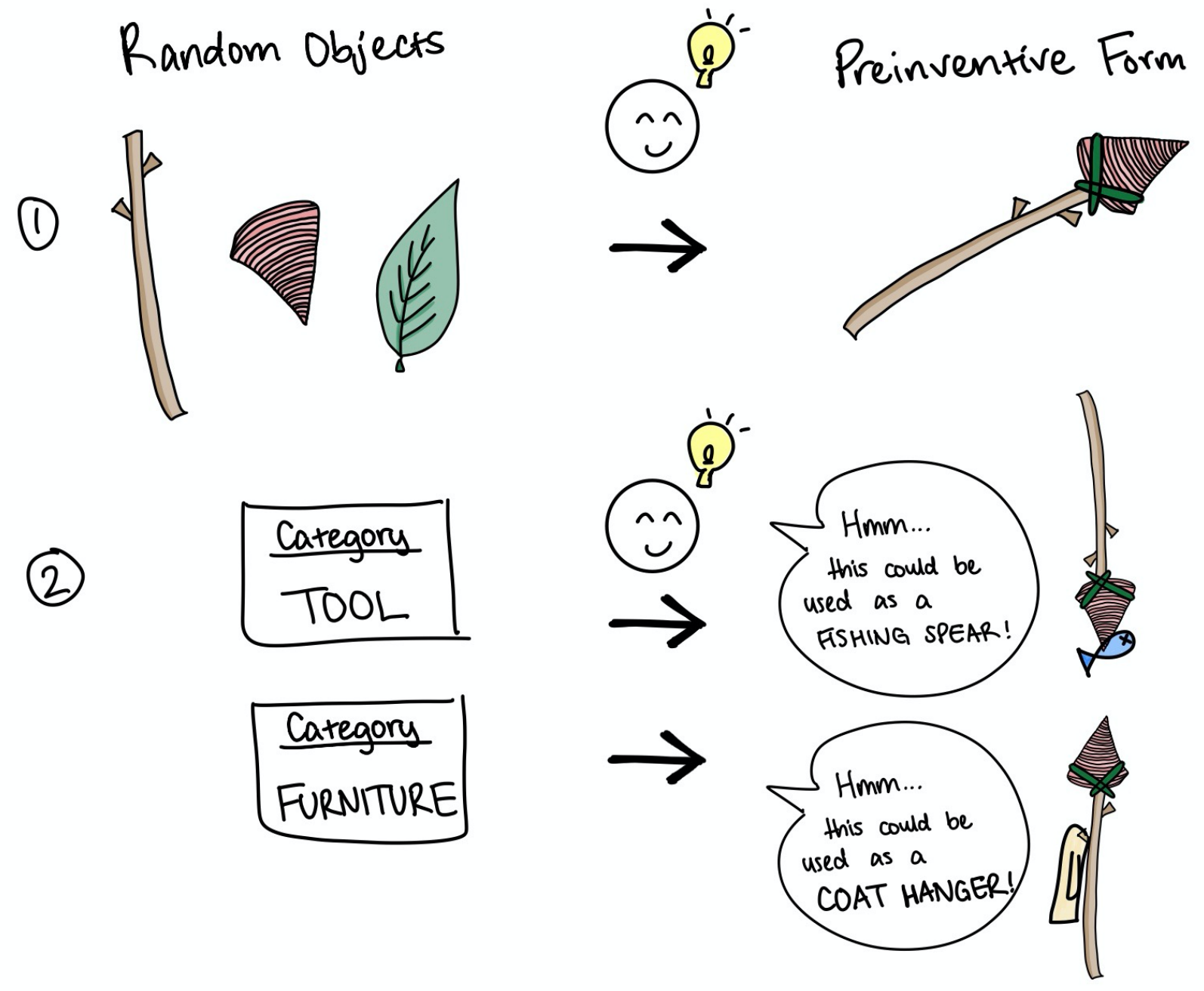

To survive on the island, you need to look for materials that may be useful for building shelter or catching food. For example, you might find palm leaves, twigs, and shells on the shore. What can you do with these objects? This is where your creativity comes into play! Creativity involves using your imagination to turn random materials into objects that can be used. This type of creativity involves making preinventive forms, which are the initial inventions that can be used and developed into different final products (Finke, 1990). For example, you could tie a twig and a shell together with a palm leaf to create a sharp stick - the preinventive form -- which can then be used as a fishing spear or coat hanger. To test people's ability to create preinventive forms, a psychologist ran an experiment as outlined in Figure 1. First, he gave participants three random objects (e.g., a block, wire, wheel, etc.) and asked them to create any practical device using the three materials. To further test people's creativity, he also asked the participants to explain how their invention could be used when given any random category (e.g., furniture, transportation, tools, etc.). For example, if given the 
category of tools, the participant could explain how their preinventive form may be used as a fishing spear. The psychologist found that most of the subjects could successfully make and explain at least one creative invention. This experiment shows that people can use their creativity to make preinventive forms to solve different problems. Like the participants in this study, using your creativity to turn random objects found on the island into useful tools will help you adapt to the island and survive!

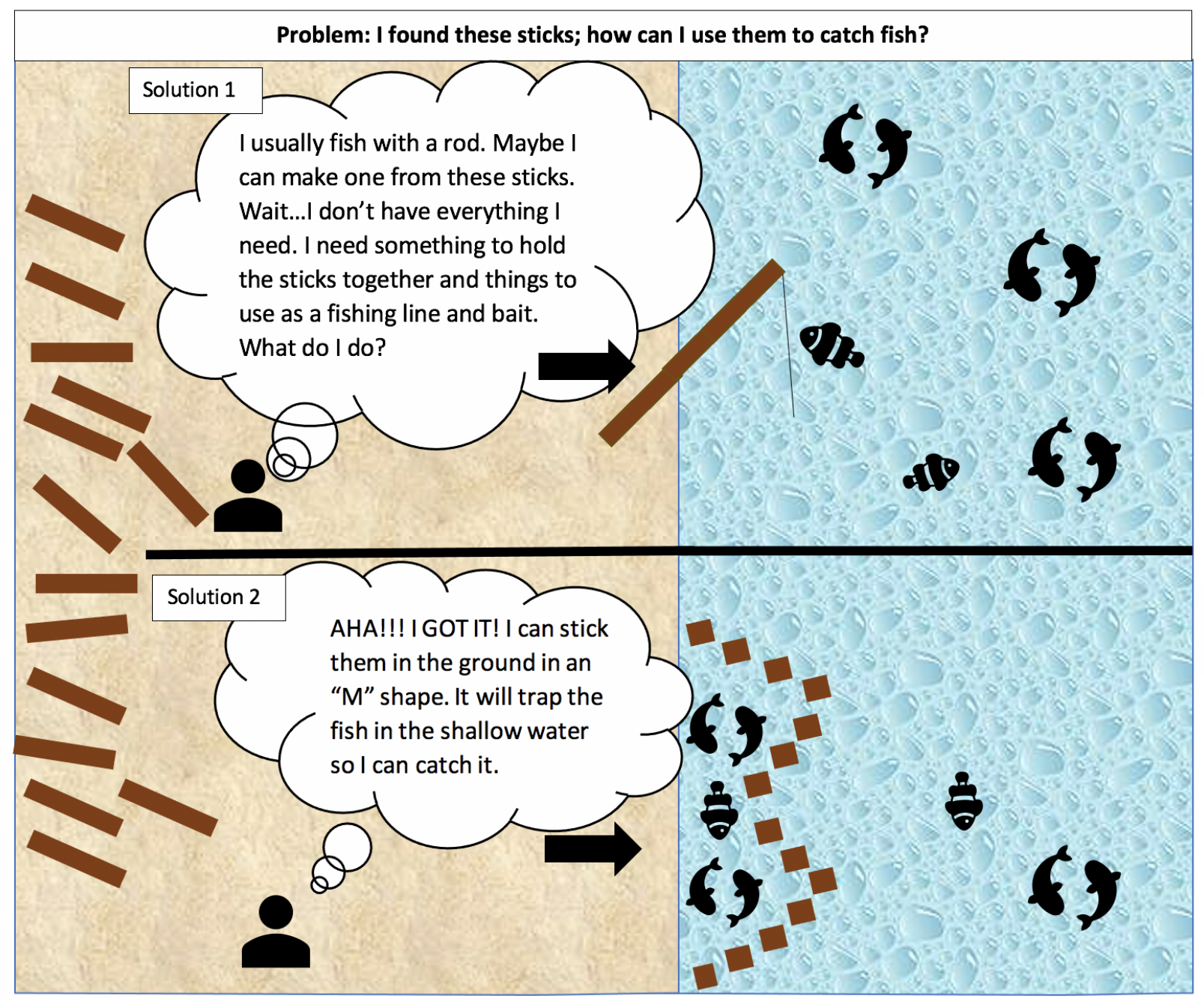

You may find that your most creative ideas come to you when you are by yourself. Studies have shown that solitude, a state of being alone, may actually improve creative thinking because there are less distractions, giving you time and space to imagine. To test this, one study compared the level of imagination between a control group with no isolation and two test groups that were isolated in Antarctica for different lengths of time (Barabasz, 1984). Results showed that compared to the control group, both test groups had significant increases in imagination after isolation. Therefore, isolation on 
a deserted island may actually allow you to use your imagination more because you can become absorbed in your thoughts. Your creative imagination will then spark the ideas to help you survive and escape from the island!

\section{FISHING FOR FOOD: OVERCOMING MENTAL SET AND GAINING INSIGHT}

Finding food is one problem you must solve quickly. However, your mental set, the existing idea you have about how to solve a problem, can make it challenging to find a quick and easy solution. To test the effect of mental set on problem solving, a psychologist investigated how the repeated use of a solution affects the way people solve problems (Luchins, 1942). Participants had to figure out how to get a desired volume of water when given three empty water jugs of different sizes. The psychologist split the participants into two groups: the mental set group and the control group. He explained one solution to the mental set group but did not give any hints to the control group. The study showed that while the majority of the mental set group became fixed on the solution provided by the researcher, the control group thought of simpler methods on their own. This study shows that the habit of using one method can prevent you from solving a problem more simply. For example, the existing idea that fish are caught by a fishing rod could cause you to overlook a simpler method. As shown in Figure 2, one easy solution could be making a fish trap by placing sticks into the sand near the water in an " $\mathrm{M}$ " shape with a small opening in the middle to allow fish to enter. By opening up to the possibility of multiple solutions, rather than focusing on the commonly used method, you can think of more effective ideas.

There are times when you might suddenly realize easier solutions to complex problems. This concept is known as insight, which is when you realize an answer that was not initially obvious while problem solving. Insight occurs when you mentally reorganize a problem, leading to an 'aha' moment. To investigate insight, researchers gave subjects both non-insight (e.g., "What is $(2 x+y)(3 x-y)$ ?") and insight problems (e.g., "What three balls can you move to get the triangle to point down instead of up?"; Metcalfe \& Wiebe, 1987). Non-insight problems like algebra problems have formulas leading to a single answer, whereas insight problems can be solved in a variety of creative ways. While completing these questions, every 15 seconds participants rated how close (hot) or not close (cold) they felt they were to solving the problem. The study found that non-insight problems showed gradual feelings of closeness towards reaching the answer, whereas insight problems were solved suddenly. This study shows that when faced with a challenge like looking for food, insight may provide you with a sudden creative solution. 


\section{DESINGING SHELTER: CONQUERING FUNCTIONAL FIXEDNESS}

To survive the cold night, you will also need to build a shelter. However, all you see are scraps from the boat wreckage and plants. How can you build a shelter with items that are not meant to be used for building? This question highlights a specific type of mental set called functional fixedness, which is the inability to think about using an object in a different way than traditionally used. When tasked with building structures, people often encounter design fixation, a specific type of functional fixedness that describes the struggle to consider non-traditional methods to design structures. Psychologists tested the effect of design fixation by giving students materials to complete a design challenge (e.g., designing a spill-proof coffee cup) in as many different ways as possible (Jansson \& Smith, 1991). Half of the students received an image of a sample design solution, while the other half received no help. The researchers found that while both groups made the same number of designs, the group with the image struggled to overcome design fixation. Their focus on the sample design prevented them from creating new structures that were different from the sample. As you begin designing your shelter, try not to think about the original function of the sail or the ropes from the boat. Instead, imagine them as materials to build a roof to keep the rain off your head!

Once you are aware of the challenge that functional fixedness creates, you need to find ways to overcome this mental set. Scientists examined whether touching materials might allow people to overcome functional fixedness when solving problems (Glucksberg, 1964). In their study, students needed to attach a candle to a wall using items given to them in a box while blindfolded. Most of the students realized they could use the box itself as part of their solution and reported that they came to this conclusion upon touching $\mathrm{t}$ 


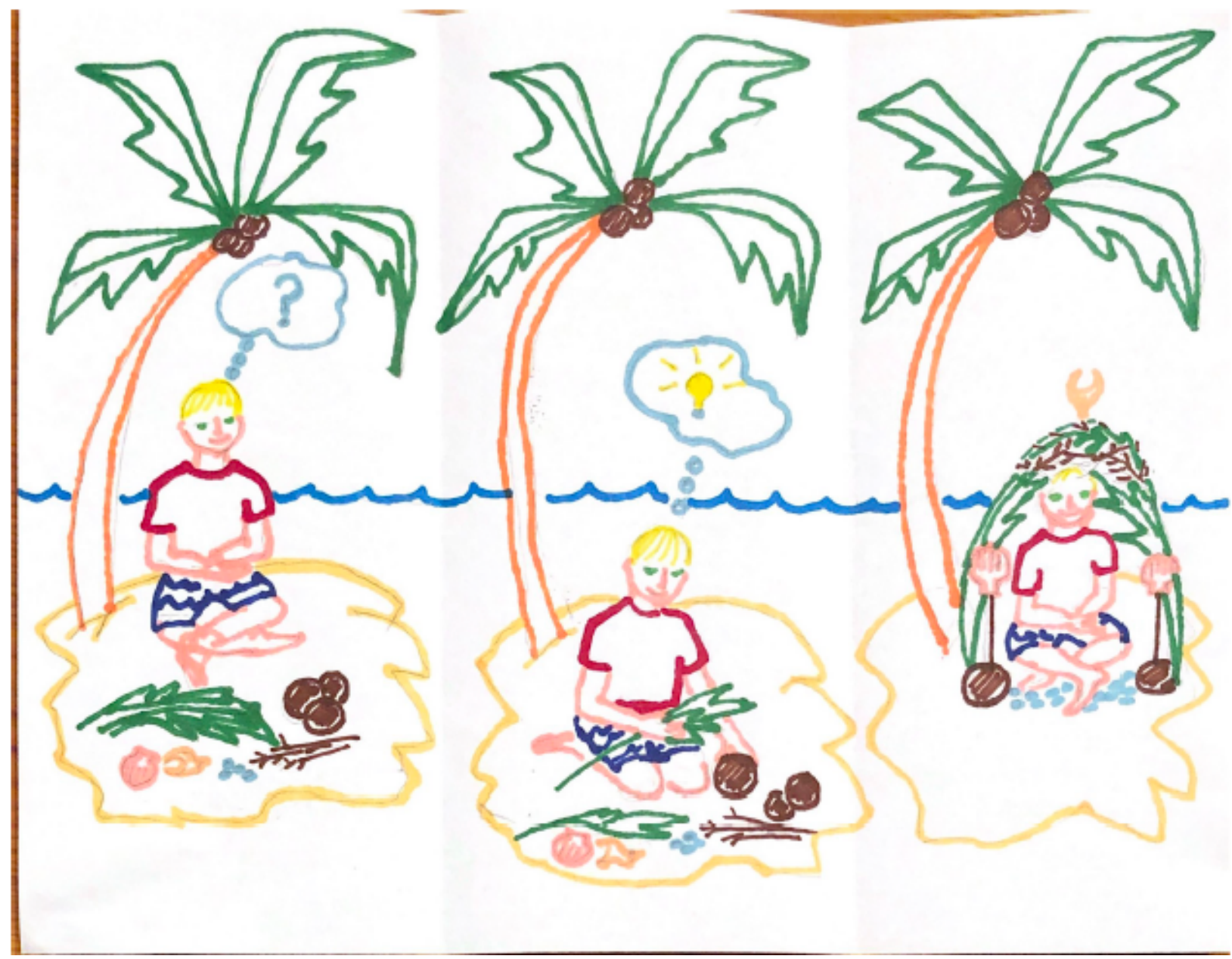

he box. As shown in Figure 3, this experiment highlights the important role touch and sensation play in overcoming functional fixedness. If you find yourself unsure of which building materials to use, try touching them. You might find that the rigid surface of palm leaves is perfect for keeping rain out or that a circular life raft from the boat is the perfect size for a window.

\section{CONCLUSION}

While survival presents a number of obstacles, this guide should prepare you to solve challenging problems. When you need to find a creative solution, designing preinventive forms and finding solitude can help. As you begin your hunt for food, start by separating yourself from your mental set; you might just find a simpler solution through insight. While building a shelter, you can overcome functional fixedness by touching objects and thinking of creative ways to use them in your design. If you can do all these things, you just might survive -- wait, there's a flare in the distance! It's a 
helicopter coming to rescue you and Alex! Well, maybe this will help the next time you two find yourselves stranded on an island!

\section{REFERENCES}

Barabasz, A. (1984). Antarctic Isolation and Imaginative Involvement-Preliminary Findings: A Brief Communication. International Journal Of Clinical And Experimental Hypnosis, 32(3), 296-300.

Finke, R. (1993). Chapter 9 Mental Imagery and Creative Discovery. In B. RoskosEwoldsen, M. Intons-Peterson \& R. Anderson, Imagery, creativity, and discovery, 255-285. Amsterdam: North-Holland.

Glucksberg, S. (1964). Functional fixedness: problem solution as a function of observing responses. Psychonomic Science, 1(1-12), 117-118.

Jansson, D., \& Smith, S. (1991). Design fixation. Design Studies, 12(1), 3-11.

Luchins, A. (1942). Mechanization in problem solving: The effect of Einstellung. Psychological Monographs, 54(6), i-95.

Metcalfe, J., \& Wiebe, D. (1987). Intuition in insight and noninsight problem solving. Memory \& Cognition, 15(3), 238-246.

\section{AUTHOR BIBLIOGRAPHY}




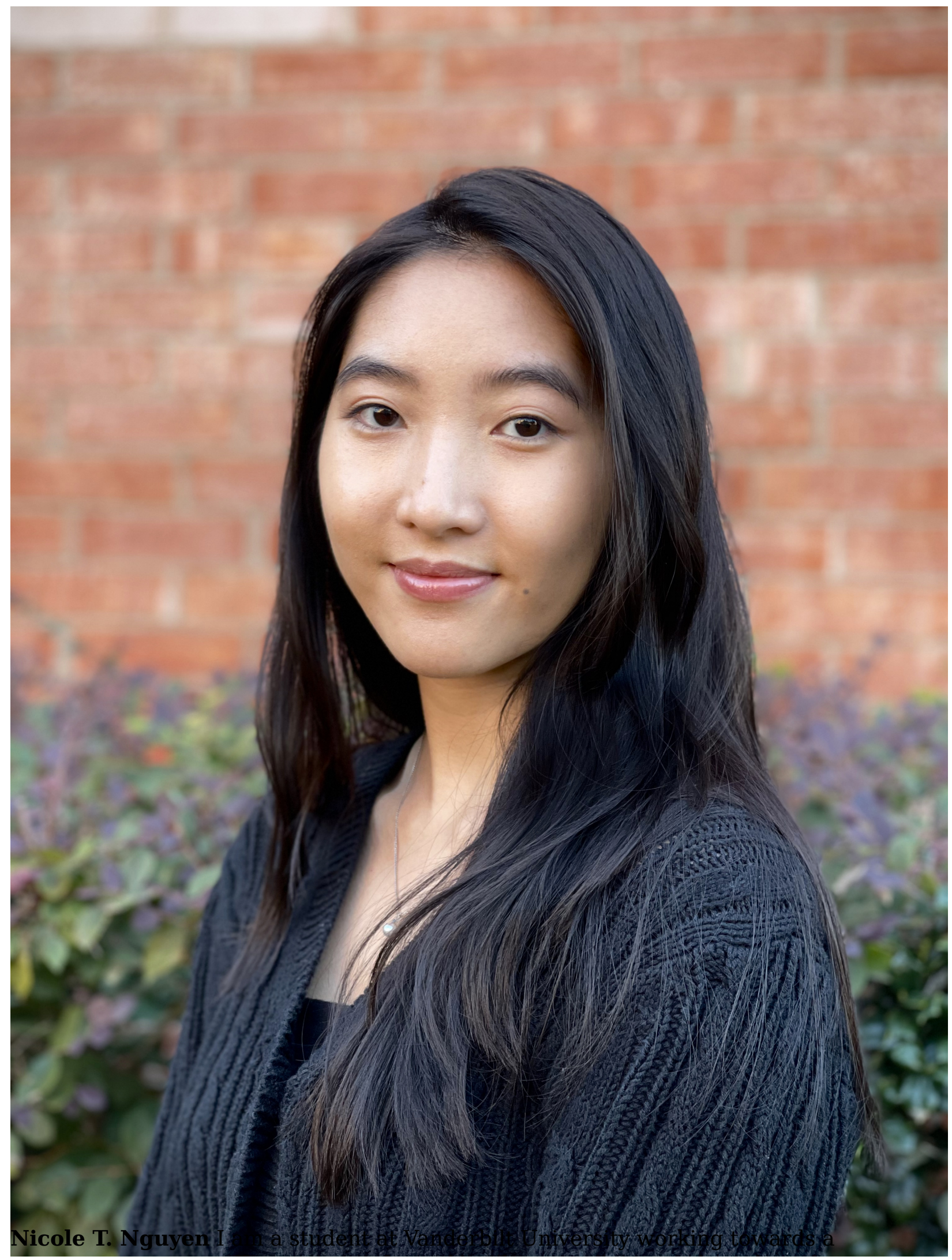

Neuroscience major while in the Pre-Medicine track. Some of my favorite topics of 
study include memory, learning, and neurodegenerative diseases. In the future, I hope to further our understanding and treatment of neurodegenerative diseases in addition to becoming a doctor. Outside of academics I love photography, traveling, painting, and spending time with friends and family.

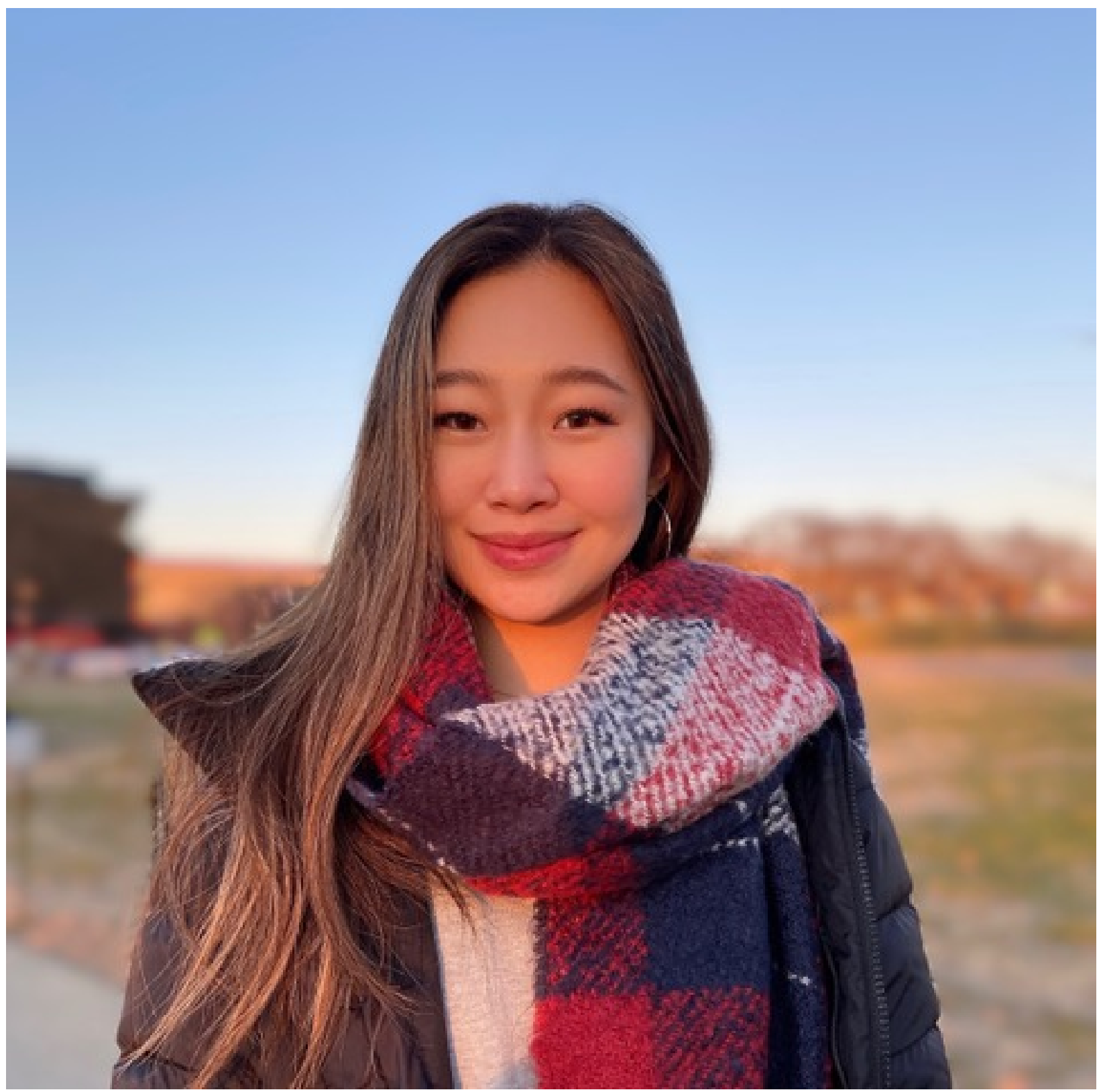

Jacqueline Oh I'm a senior from Edmond, Oklahoma majoring in Medicine, Health, and Society and minoring in Art History while on the Pre-Medicine track at Vanderbilt University. With the passion to serve and a particular interest in global health and health disparities, I hope to become a physician in the future. In my downtime, I also 
enjoy traveling with friends and family, playing board games, doodling, and cooking/baking to de-stress. 


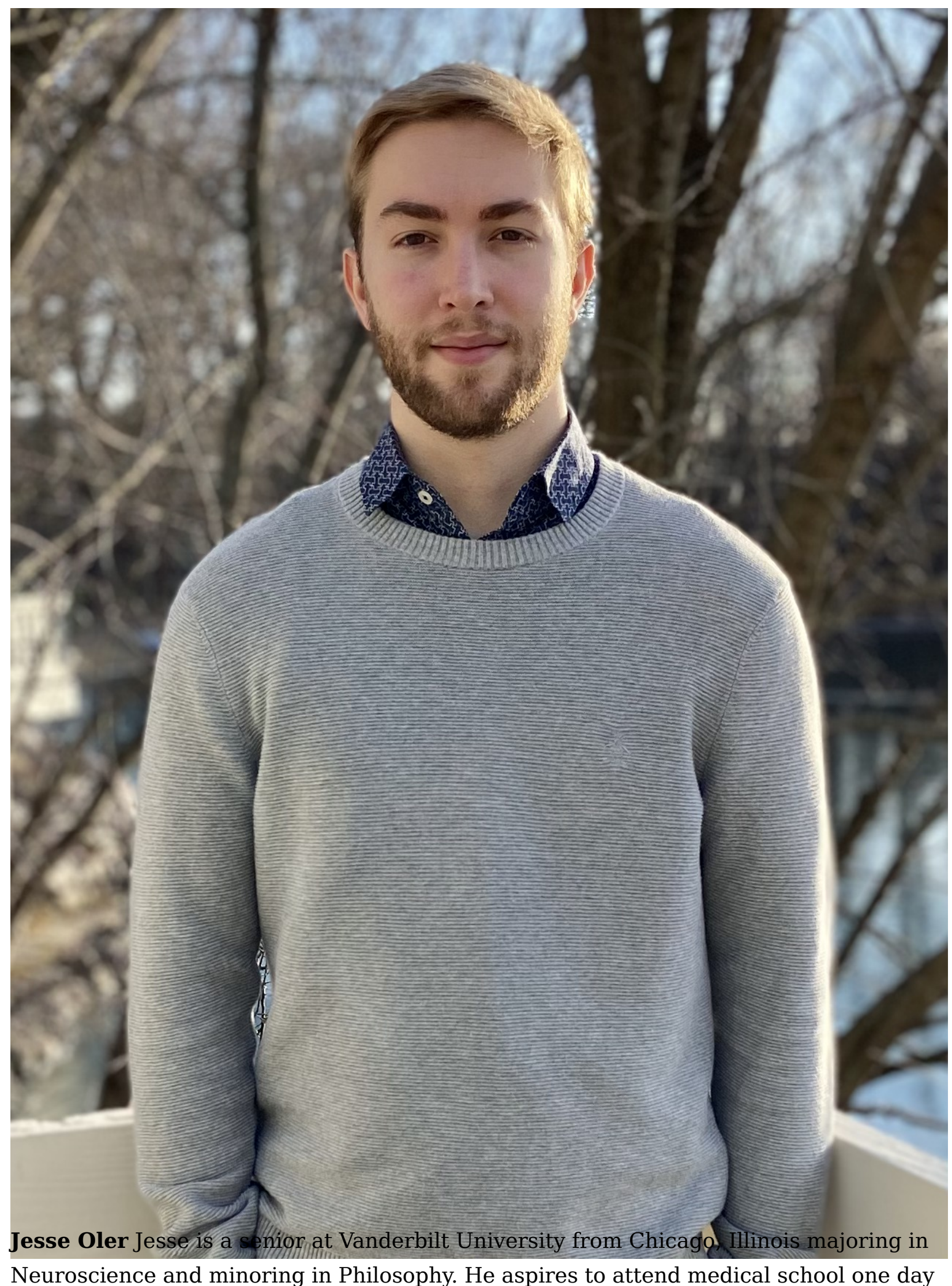


and become a research psychiatrist or neurologist specializing with a focus on neurodevelopmental disorders and psychopathology. Outside of the classroom, he is a research assistant at Blackford Lab, where he studies schizophrenia and pediatric anxiety. In his free time, he enjoys playing volleyball for Vanderbilt's men's club team, working on service projects, and editing his comedy screenplay. 